Rapid Reviews COVID-19

\title{
Review 3: "COVID-19 is Feminine: Grammatical Gender Influences Future Danger Perceptions and Precautionary Behavior"
}

\section{Laura A. Michaelis 1}

${ }^{1}$ Professor, University of Colorado at Boulder, Linguistics, USA

Published on: Dec 25, 2020

DOI: $10.1162 / 2 \mathrm{e} 3983 f 5 . e f 3652 \mathrm{f3}$

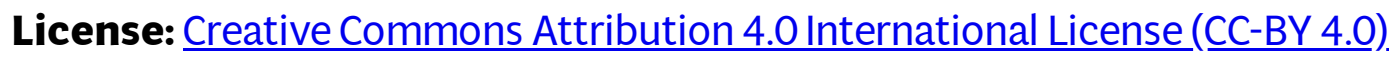




\section{$\underline{\text { RR:C19 Evidence Scale rating by reviewer: }}$}

- Strong. The main study claims are very well-justified by the data and analytic methods used. There is little room for doubt that the study produced has very similar results and conclusions as compared with the hypothetical ideal study. The study's main claims should be considered conclusive and actionable without reservation.

\section{$* * * * * * * * * * * * * * * * * * * * * * * * * * * * * * * * * * * * * * * * * *$}

\section{Review:}

In a series of four experiments using French-, Spanish- and Italian-language materials, the authors examine the effect of grammatical gender of nominal references to COVID19/Coronavirus on (a) survey-based assessments of future danger and behavioral intentions (in brief, those who saw the feminine-gender term reported a lower degree of precautionary intent), and (b) search behavior (in brief, searches using the feminine as against masculine search terms, e.g., la covid, la coronavirus) declined during periods of heightened anxiety about the disease, e.g., when deaths and cases were on the rise. The authors acknowledge that the facts of reference are complex. Strictly speaking, the term COVID-19 (and its translation equivalents in the Romance languages) refers to the disease, and the term Coronavirus to the virus that causes the disease. Nonetheless, a web search reveals numerous instances of English expressions like a cure for Coronavirus and Coronavirus symptoms, in which the term for the virus is used in reference to the disease. This pattern appears pervasive in Romance as well, and since the head noun (virus or maladie) is optional, the grammatical gender of the nouns COVID and COVID-19 and covid appears labile: in a French-language web search, for example, one can find instances of Les enfants de tous âges peuvent contracter le COVID-19 alongside Boris Johnson a contracté la COVID-19. This variation is critical to Study 3; without it, the influence of gender is confounded with that of reference, since the effects at issue could come from the fact that in one context the virus is referred to, whereas, in another, the disease is referred to. It seems unlikely that the choice of article preceding the nominal expression COVID (19) is conditioned by the writer's desire to convey 'virus' or 'malady', or that the article variation alone is sufficient to induce the interpreter to reconstruct a missing noun 'virus' or 'malady' as appropriate to the particular article used. So I feel confident that the effects reported (on self-reports of future behavior, on search behavior, etc.) are truly driven by grammatical gender, and what's more that such effects are restricted to grammatical-gender languages (the study shows them to be absent in English). But 
now, as a semanticist, I want to address the implications of this very interesting work for theories of lexical category structure and interpretation. I will also reflect on linguistic prescriptivism, a language ideology that this paper presents uncritically, but need not adopt. The study hinges on the claim that the speaker or writer's choice of masculine or feminine gender means something to readers; they say: "the grammatical gender mark activates stereotypical concepts related to masculinity and femininity". At the same time, they say: "[a]ssignment of grammatical gender is arbitrary, and thus should not logically influence judgments; speakers of gendered languages are wellaware that grammatical gender has no meaning for non-human entities". I think the authors could offer a more principled account of the semantics of gender categories, as lexical classes, than they do. The authors appear to embrace a paradox-claiming, on the one hand, that grammatical gender marking has no semantic content, and, on the other, that there are semantic effects of the use of a feminine gender marker, viz. its use evokes properties that certain repressive ideologies attribute to women, like weakness and frailty. I suggest they consider a theory of lexical category structure based on prototypes, as per Lakoff's highly influential 1987 treatment of 'radial' category structure. In this theory, gender markers, like the Dyirbal classifier alluded to in the book's title, are categories of entities that are grouped together based on certain culturally salient, subjective common properties. A linguistic category is in some sense a historic record of the series of imaginative leaps that extended the boundaries of the category over time. The authors seem to come close to this kind of theory when they say: "despite the arbitrariness of assignment of grammatical gender, there is accumulating evidence that referring to objects as masculine or feminine affects the meaning assigned to the objects." A degree of arbitrariness is undeniable: when we look across languages we find a particular class of entities (e.g., spoons) expressed as both masculine (German der Löffel) and feminine (French la cuillère). However, Williams et al. (2019) found, in a large-scale typological study based on word embeddings, that 18 typological distinct languages exhibit a significant correlation between grammatical gender and lexical semantics. The only way one can interpret the current study as a semantic study is if gender markers are seen as meaningful for both human and non-human referents. In this theory, properties imputed to entities based on gender biases are part of the clusters of semantic properties conventionally associated with the masculine and feminine gender categories, respectively. Another linguistic framework that could be applied to good effect here is the socio-cultural lens on language prescriptivism. Throughout the paper the authors refer to the use of masculine gender for COVID-19 as the "wrong gender", as against the "correct" or "proper" feminine gender. In linguistics, however, we are concerned with the facts of 
usage, not what some societal bodies (like the Académie Française) might think about a given usage practice. The French Academy might have logic behind it in recommending the use of feminine gender in reference to a disease, but the gender variability we actually encounter suggests that language users don't employ this rationale when they select grammatical gender. So I question the authors' conclusion that "even though the motivation of Académie Française for urging proper grammar usage is surely well-intentioned, it may have had unfortunate unintended consequences". Is this really the moral of this story? The prescriptions of the AF have little effect on language users' daily practice, so they could not stop the dispreferred masculine reference even if that were in the interest of society. I think a better moral is that gender-based ideologies (like 'women are physically weak') are encapsulated by linguistic categories and thus that feminine reference to COVID reflects a particular metaphorical model of disease, or personified causes in general, which in turn evokes a particular metaphorical way of framing the disease, which in turn affects risk behavior.

\section{References:}

Lakoff, George. 1987. Women, Fire and Dangerous Things: What Categories Reveal about the Mind. Chicago: University of Chicago Press.

Williams, A., Cotterell, R., Wolf-Sonkin, L., Blasi, D., \& Wallach, H. (2019). Quantifying the semantic core of gender systems. arXiv preprint arXiv:1910.13497. 